\title{
Ekologi Fitoplankton : Ditinjau dari Aspek Komposisi, Kelimpahan, Distribusi, Struktur Komunitas dan Indeks Saprobitas Di Perairan Morosari, Demak
}

\author{
Cinthya Ruhanto Putri*, Ali Djunaedi, Subagyo \\ Departemen IImu Kelautan, Fakultas Perikanan dan IImu Kelautan, Universitas Diponegoro \\ JI. Prof. H. Soedarto S.H, Tembalang,Semarang, Jawa Tengah 50275 Indonesia \\ ${ }^{*}$ Corresponding author, e-mail: cinthyacynnn@gmail.com
}

\begin{abstract}
ABSTRAK : Perairan Morosari yang terletak di Kecamatan Sayung, Kabupaten Demak merupakan tempat terjadinya percampuran antara air darat dan air laut. Disekitar perairan Morosari terdapat pemukiman penduduk, industri wisata dan aktifitas nelayan. Aktivitas masyarakat dan wisatawan tersebut akan menimbulkan perubahan yang mengarah pada peningkatan pencemaran yang berimbas kepada keberadaan fitoplankton. Tujuan dari penelitian ini adalah untuk mengetahui komposisi, kelimpahan, distribusi, struktur komunitas dan indeks saprobitas fitoplankton di perairan Morosari. Metode yang digunakan dalam penelitian ini adalah deskriptif eksploratif dan penentuan lokasi menggunakan metode purposive sampling. Penelitian ini terbagi atas 3 sub-area di 3 area yang berbeda. Pengambilan sampel zooplankton dengan cara aktif dengan menarik planktonet secara horizontal. Hasil penelitian diperoleh 24 genera fitoplankton dari 3 kelas di perairan Morosari. Kelimpahan fitoplankton bervariasi antara 12.556 19.108 individu $/ \mathrm{m}^{3}$. Distribusi fitoplankton tidak merata dan cenderung mengikuti arah arus. Indeks keanekaragaman menunjukkan nilai 1,70-2,25 yang termasuk dalam kategori sedang. Indeks keseragaman fitoplankton menunjukkan nilai $0,71-0,81$ yang termasuk dalam kategori Tinggi. Indeks dominansi di perairan Morosari berkisar antara 0,18-0,29 dan termasuk ke dalam kriteria tidak ada jenis yang mendominasi. Indeks Saprobik menunjukkan nilai $0,6-1,3$ yang termasuk dalam kategori $\beta$-Mesosaprobik.
\end{abstract}

Kata Kunci: Fitoplankton, Dominansi, Saprobitas, Morosari

The Ecology of Phytoplankton: From the Aspects of Composition, Abundance, Distribution,
Community Structure and Saprobic Index in Morosari Waters, Demak

ABSTRACT : Morosari waters located in District Sayung, Demak Regency is waters area there is a mixture of land and sea water. Surrounding the Morosari waters there are residential, tourist industry and fishing activities. These activities will be affected changes that lead to increased pollution that affects the presence of phytoplankton. The purpose of this research was to know the composition, abundance, distribution, community structure and saprobity index of phytoplankton in Morosari waters, Sayung Subdistrict, Demak District. This research used deskriptive eksplorative method and determination location used purposive sampling method. The results obtained 24 genera phytoplankton of 3 classes. The abundance of phytoplankton ranges from 12.556-19.108 individu $/ \mathrm{m}^{3}$. The distribution of phytoplankton is uneven and tends to follow the current direction. The phytoplankton Diversity Index indicated the values of 1,70-2,25 which were in the medium category. The phytoplankton evenness index indicated a value of 0,71 to 0,81 belonged to the High category. The dominance index in Morosari waters indicated no particular genus dominating with the values of 0,18-0,29. The Saprobik Index indicated the values of 0,6-1,3 which were into the category $\beta-$ Mesosaprobic

Keywords: Phytoplankton, Dominance, Saprobitas, Morosari

\section{PENDAHULUAN}

Wilayah pantai merupakan ekosistem yang khas memiliki fungsi sebagai penyangga kehidupan masyarakat pantai. Wilayah pantai banyak dimanfaatkan untuk kegiatan ekonomi, diantaranya adalah industri rekreasi/wisata, pemukiman dan pertambakan (Sugito dan Sugandi, 
2010). Fitoplankton merupakan kelompok organisme yang dapat menjadi bioindikator untuk mengevaluasi kualitas dan tingkat kesuburan suatu perairan (Thoha, 2004). Keberadaan fitoplankton pada suatu perairan diperlukan untuk menunjang kehidupan biota lainnya. Fitoplankton berperan penting dalam rantai makanan yaitu sebagai produsen primer. Aktivitas produsen primer mengawali transfer energi didalam ekosistem perairan dengan mengubah unsur hara menjadi senyawa organic dalam bentuk biomassa tubuhnya melalui proses fotosintesis. Proses fotosintesis penting karena akan menghasilkan oksigen yang dibutuhkan bagi kehidupan biota perairan (Elfinurfajri, 2009).

Perairan Morosari, Kecamatan Sayung, Kabupaten Demak telah mengalami degradasi akibat berkurangnya tanaman mangrove karena terjadinya rob dan penurunan muka tanah (land subsidence). Selain itu, disekitar perairan Morosari terdapat pemukiman penduduk, industri wisata dan aktifitas nelayan. Meningkatnya aktivitas masyarakat dikhawatirkan akan mempengaruhi kualitas perairan dan menyebabkan penurunan produktivitas perairan dan perubahan komposisi dan kelimpahan fitoplankton. Mengingat pentingnya peranan fitoplankton sebagai produsen primer yang menghubungkan dengan organisme lainnya, sehingga dilakukan penelitian tentang fitoplankton Komposisi, Kelimpahan, Distribusi, Indeks Saprobitas dan struktur komunitas fitoplankton untuk mengetahui komposisi, kelimpahan, indeks keanekaragaman, indeks keseragaman dan indeks dominansi fitoplankton.

\section{MATERI DAN METODE}

Metode yang digunakan dalam peneltian ini adalah metode deskriptif dimana metode ini bertujuan untuk menggambarkan suatu kondisi atau keadaan tanpa mengambil keputusan secara umum, sistematis, actual dan akurat (Arikunto, 2002). Metode yang digunakan untuk penentuan lokasi sampling adalah purposive sampling method yaitu mengambil beberapa lokasi dengan pertimbangan yang mempunyai kaitan erat dengan ciri-ciri yang sudah diketahui sebelumnya (Hadi, 1979). Penelitian ini terbagi atas 3 area dengan 3 sub-area disetiap lokasi dengan asumsi dapat mewakili perairan tersebut. Berikut peta penelitian selengkapnya pada Gambar 1.

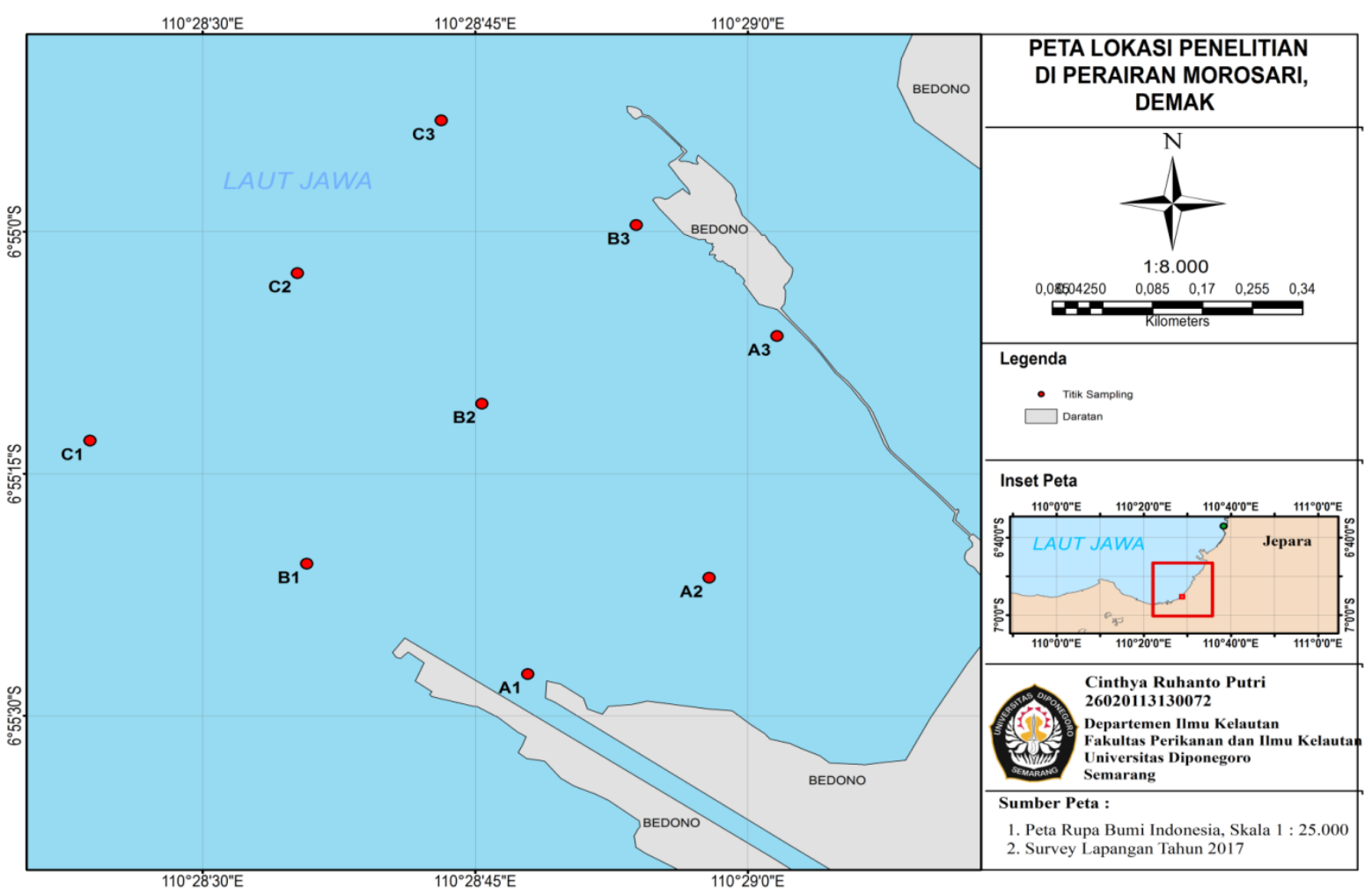

Gambar 1. Peta Penelitian di Perairan Morosari, Kecamatan Sayung, Kabupaten Demak. 
Pengambilan sampel dilakukan secara aktif dengan menarik planktonet secara horizontal (Fachrul, 2008). Identifikasi sampel dilakukan dengan bantuan mikroskop perbesaran 10x10, sampel diletakkan di Haemocytometer. Sampel kemudian diamati jumlah dan diidentifikasi genusnya yang mengacu pada buku identifikasi dari Yamaji (1979) dan Sachlan (1982).

Data fitoplankton dianalisa dengan menghitung Kelimpahan (K) Arinardi et al, (1997), Indeks Keanekaragaman (H') Shannom- Weaver (1963) dalam Arinardi et al, 1997, Indeks Keseragaman (e) Odum (1993) dan Indeks Dominansi (C) Odum (1993) dan Indeks Saprobik Dresschen dan Van der Mark (1976)

\section{HASIL DAN PEMBAHASAN}

Berdasarkan hasil pengamatan fitoplankton yang telah dilaksanakan di Perairan Morosari, diperoleh 24 Genera dari 3 kelas, yaitu 20 genus dari Bacillariophyceae, 1 Genus dari Cyanophyceae dan 3 genus dari Dinophyceae. Kelompok Bacillariophyceae merupakan kelas yang paling sering ditemukan di Perairan Morosari (Gambar 2). Melimpahnya kelas Bacillariophyceae di Perairan Morosari diduga berkaitan dengan kondisi di Perairan Morosari yang mendukung kehidupan jenis-jenis dalam kelas ini, terutama salinitas.

Menurut Sachlan (1982) menjelaskan bahwa fitoplankton yang hidup pada nilai salinitas di atas $20 \%$ sebagian besar merupakan plankton dari kelompok Bacillariophyceae. Kelas Bacillariophyceae memiliki tingkat kemampuan pertumbuhan yang relatif cepat bahkan pada kondisi lingkungan yang kurang menguntungkan sekalipun. Sehingga, kelompok ini merupakan komponen fitoplankton yang paling umum dijumpai di laut dan terdapat disemua area, dari tepi pantai hingga ke tengah samudera (Nontji, 2008).

Selain salinitas, suhu juga diduga mempengaruhi melimpahnya Bacillariophyceae di Perairan Morosari. Suhu di perairan Morosari menunjukkan nilai yang cukup baik untuk pertumbuhan fitoplankton yaitu berkisar antara $25,8-27.6^{\circ} \mathrm{C}$. Menurut Hutabarat dan Evans (1986) dalam Pamungkas (2014) suhu optimum untuk pertumbuhan fitoplankton pada perairan tropis berkisar pada $25-32{ }^{\circ} \mathrm{C}$. Beberapa kelas dari fitoplankton yang dapat bertahan pada suhu relatif tinggi $\left(>29^{\circ} \mathrm{C}\right)$ adalah Cyanophyceae, sedangkan bagi Chlorophyceae dan Bacillariophyceae, suhu tinggi menjadi faktor penghambat (Nybakken, 1992 dalam Pamungkas, 2014).

Kelas Cyanophyceae memiliki jumlah genus yang paling sedikit ditemukan. Hal ini diduga karena Cyanophyceae kurang mampu tumbuh pada salinitas yang cukup tinggi, meskipun beberapa genus dari Cyanophyceae mampu hidup pada kondisi habitat yang sangat ekstrim. Selain kelas Bacillariophyceae terdapat pula kelas Dinophyceae dan Cyanophyceae. Kelas Dinophyceae merupakan urutan kedua yang sering ditemukan dari Perairan Morosari. Menurut Nontji (2008) Dinophyceae merupakan grup fitoplankton yang sangat umum ditemukan di laut setelah Bacillariophyceae.

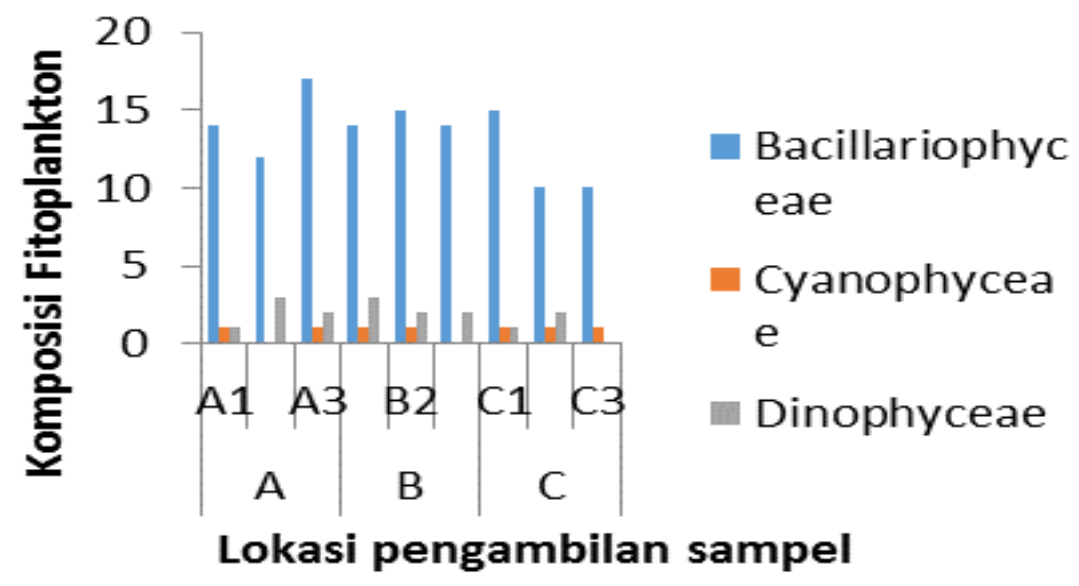

Gambar 2. Komposisi Genus Fitoplankton di Perairan Morosari, Kecamatan Sayung, Kabupaten Demak. 
Hasil pengamatan terhadap kelimpahan fitoplankton di perairan Morosari berkisar antar 12.556-19.108 individu $/ \mathrm{m}^{3}$. Kelimpahan fitoplankton di perairan Morosari menunjukkan kelimpahan tertinggi di Area A3 sebesar 19.108 individu $/ \mathrm{m}^{3}$ dan terendah terdapat di Area B1 yaitu 12.556 individu/m³ (Gambar 3).

Kelimpahan Bacillariophyceae lebih banyak jika dibandingkan dengan dua kelas lainnya. Kepadatan Bacillariophyceae lebih dominan dari kelas lainnya di ekosistem lamun perairan Teluk Awur Jepara. Hal ini diduga kemampuan toleransi terhadap kondisi perairan dan mampu beradaptasi lebih baik di lingkungannya sehingga dapat berkembang biak dengan cepat dan memanfaatkan kandungan nutrient yang ada dengan baik (Arinardi et al., 1997).

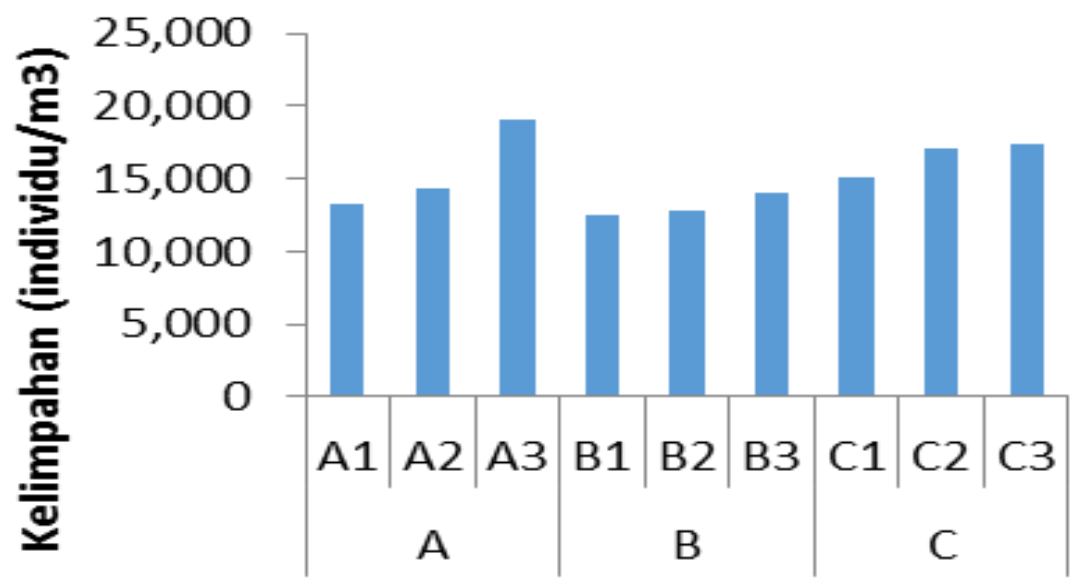

\section{Lokasi Pengambilan sampel}

Gambar 3. Kelimpahan Fitoplankton (individu $/ \mathrm{m}^{3}$ ) di perairan Morosari, Kecamatan Sayung, Kabupaten Demak

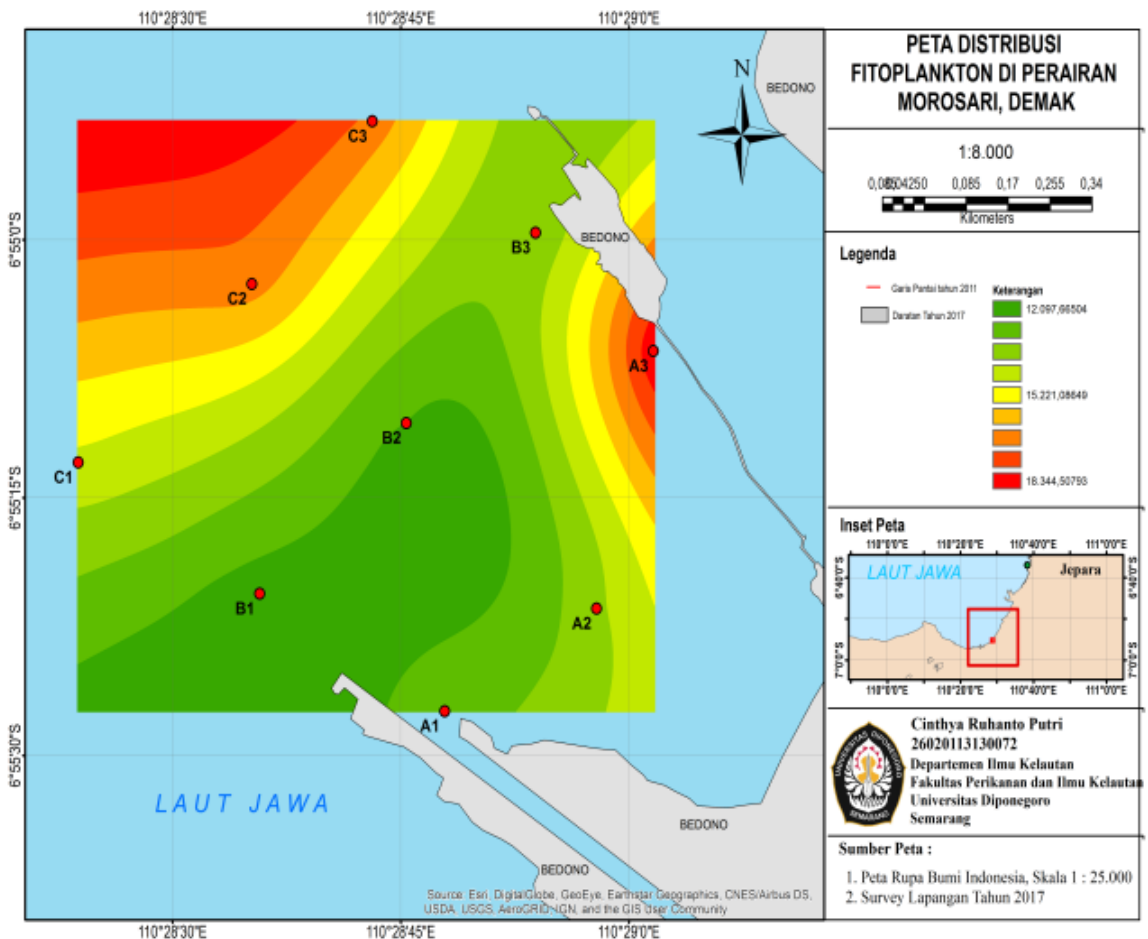

Gambar 4. Peta persebaran Distribusi fitoplankton di perairan Morosari, Kecamatan Sayung, Kabupaten Demak 
Berdasarkan hasil analisis kelimpahan fitoplankton disetiap sub-area di Perairan Morosari, dapat diketahui pola persebaran fitoplankton. Berdasarkan peta persebaran distribusi fitoplankton di Perairan Morosari mengalami persebaran yang tidak merata dan cenderung mengikuti arah Arus (Gambar 4). Hal ini diduga karena nilai arus yang diukur tidak terlihat fluktuasi nyata dan cenderung memiliki kecepatan rendah yaitu $0,15 \mathrm{~m} / \mathrm{s}$, sehingga kelimpahan total fitoplankton terlihat melimpah hanya di beberapa titik penelitian. Kondisi distribusi fitoplankton dipengaruhi oleh berbagai faktor, seperti faktor atmosfer, lokasi dan kondisi lingkungan perairan tersebut (Setiadi, 2004).

Hawkes (1978) menyatakan, kecepatan arus akan berperan dalam proses migrasi dan penyebaran plankton sebagai organisme yang pasif sehingga pergerakannya sangat ditentukan oleh arus. Hal ini berarti kecepatan arus akan mempengaruhi komposisi dan kelimpahan plankton. Hasil pengamatan terhadap Fitoplankton di Perairan Morosari diperoleh nilai indeks keanekaragaman berkisar 1,70-2,25. Tertinggi terdapat di Area B1 yaitu 2,25 dan terendah terdapat di Area C3 yaitu 1,70 (Tabel 1).

Indeks keanekaragaman $\left(\mathrm{H}^{\prime}\right)$ plankton dapat digunakan sebagai acuan untuk menentukan kualitas perairan. Keanekaragaman fitoplankton menunjukkan tingkat kompleksitas dari struktur komunitas perairan (Soegianto, 2004). Penurunan indeks keanekaragaman ( $\mathrm{H}^{\prime}$ ) dapat terjadi akibat adanya pencemaran dan eutrofikasi di suatu lingkungan perairan. Menurut Nybakken (1992) dan Odum (1993) bila keanekaragaman suatu komunitas bernilai tinggi menunjukan bahwa pada daerah tersebut memiliki ekosistem yang baik, seimbang atau stabil dan memberikan peranan yang besar untuk menjaga keseimbangan terhadap hal-hal yang merusak ekosistem. Nilai keanekaragaman yang rendah menunjukan lingkungan yang kurang mendukung kehidupan dan tidak stabil. Arinardi et al. (1997) menambahkan apabila nilai indeks keanekaragaman (H') makin tinggi maka komunitas plankton makin beragam dan tidak di dominasi oleh satu spesies saja.

Hasil pengamatan terhadap fitoplankton di Perairan Morosari diperoleh nilai indeks keseragaman tertinggi terdapat di Area A2 sebesar 0,81 dan terendah terdapat di Area C3 yaitu 0,71 (Tabel 1). Hasil tersebut menunjukkan kategori keseragaman tinggi $(E>0,6)$ mengacu pada

Tabel 1. Indeks Keanekaragaman (H'), Indeks Keseragaman (e), Indeks Dominansi (D) dan Indeks Saprobik Fitoplankton di Perairan Morosari, Kecamatan Sayung, Kabupaten Demak

\begin{tabular}{|c|c|c|c|c|c|c|c|c|}
\hline \multicolumn{9}{|c|}{ Perairan Morosari } \\
\hline Area & $\mathrm{H}^{\prime}$ & Kategori $^{\star}$ & e & Kategori** $^{\star *}$ & $\mathrm{D}$ & Kategori** $^{\star *}$ & $\mathrm{X}$ & Kategori \\
\hline $\mathrm{A} 1$ & 2,05 & Sedang & 0,74 & Tinggi & 0,25 & TAD & 1 & $\begin{array}{c}\text { Ringan s/d } \\
\text { Sedang }\end{array}$ \\
\hline $\mathrm{A} 2$ & 2,19 & Sedang & 0,81 & Tinggi & 0,18 & TAD & 1 & $\begin{array}{c}\text { Ringan s/d } \\
\text { Sedang }\end{array}$ \\
\hline A3 & 2,20 & Sedang & 0,73 & Tinggi & 0,26 & TAD & 1 & $\begin{array}{c}\text { Ringan s/d } \\
\text { Sedang }\end{array}$ \\
\hline B1 & 2,25 & Sedang & 0,77 & Tinggi & 0,22 & TAD & 0,6 & $\begin{array}{c}\text { Ringan s/d } \\
\text { Sedang }\end{array}$ \\
\hline B2 & 2,25 & Sedang & 0,77 & Tinggi & 0,22 & TAD & 1,3 & $\begin{array}{c}\text { Ringan s/d } \\
\text { Sedang }\end{array}$ \\
\hline B3 & 2,02 & Sedang & 0,72 & Tinggi & 0,27 & TAD & 0,6 & $\begin{array}{c}\text { Ringan s/d } \\
\text { Sedang }\end{array}$ \\
\hline $\mathrm{C} 1$ & 2,21 & Sedang & 0,78 & Tinggi & 0,21 & TAD & 1 & $\begin{array}{c}\text { Ringan s/d } \\
\text { Sedang }\end{array}$ \\
\hline $\mathrm{C} 2$ & 1,89 & Sedang & 0,73 & Tinggi & 0,26 & TAD & 1 & $\begin{array}{c}\text { Ringan s/d } \\
\text { Sedang }\end{array}$ \\
\hline C3 & 1,70 & Sedang & 0,71 & Tinggi & 0,29 & TAD & 0,6 & $\begin{array}{c}\text { Ringan s/d } \\
\text { Sedang }\end{array}$ \\
\hline
\end{tabular}

TAD : Tidak Ada Dominasi

*Shannon-Weaver (1949) ${ }^{* *}$ Krebs, $1985{ }^{* * *}$ Dresschen van der Mark (1976) 
(Krebs, 1985 dalam Pamungkas, 2014). Semakin besarnilai keseragaman (mendekati 1) maka populasi akan menjukan keseragaman (jumlah individu tiap genus dapat dikatakan sama atau tidak jauh berbeda) (Odum, 1993). Hasil pengamatan fitoplankton di Perairan Morosari diperoleh hasil nilai indeks dominansi tertinggi terdapat di Area C3 sebesar 0,29 dan terendah terdapat di Area $A 2$ yaitu 0,18 (Tabel 1 ).

Hasil tersebut termasuk ke dalam kategori tidak ada jenis yang mendominasi $(0<D<0,50)$. Hal tersebut menggambarkan bahwa ada genus fitoplankton yang mendominasi di perairan Morosari pada selama penelitian. Odum (1993) menyatakan nilai Indeks Dominansi berkisar antara 0 - 1. Jika nilai indeks dominansi mendekati 0 , berarti tidak ada individu yang mendominasi, sebaliknya jika nilai indeks dominansi mendekati 1 , maka ada individu yang mendominasi. Hasil pengamatan fitoplankton di Perairan Morosari diperoleh hasil nilai indeks saprobik bekisar antara $0,6-1,3$ dan termasuk dalam kategori $\beta$-mesosaprobik .

Hasil koefisien saprobik menunjukkan tingkat pencemaran di perairan Morosari tercemar sedang sampai ringan. Kisaran nilai saprobitas tersebut berdasarkan hasil pengamatan, masuk dalam golongan $\beta$-Mesosaprobik. Fase $\beta$ (betha) menunjukkan pada kondisi lebih baik dan fase $\alpha$ (alfa) menunjukkan kondisi yang buruk, sedangkan mesosaprobik menyatakan keadaan yang tercemar sedang sampai ringan. Hal ini dikarenakan hampir di setiap stasiun pada lokasi penelitian ditemukan genus Skeletonema sp. yang termasuk dalam kelompok oligosaprobik, yaitu genus yang dijadikan sebagai indikator pencemaran tingkat ringan (Anggoro, 1988). Perbedaan jumlah organisme plankton dalam suatu perairan akan mempengaruhi tingkat saprobitas di perairan tersebut. Nilai saprobitas perairan merupakan gambaran dari tingkat pencemaran suatu perairan.

\section{KESIMPULAN}

Komposisi fitoplankton di Perairan Morosari didominasi oleh kelas Bacillariophyceae. Distribusi fitoplankton di Perairan Morosari tidak terdistribusi secara merata. Struktur komunitas yang ada di Perairan Morosari dalam kondisi yang tidak stabil, dan indeks saprobik di Perairan Morosari tercemar ringan sampai dengan sedang.

\section{DAFTAR PUSTAKA}

Arikunto, S. 2002. Prosedur Suatu Penelitian; Pendekatan Praktek, Edisi Revisi Kelima, Penerbit Rineka Cipta. Jakarta

Arinardi, O.H., Sutomo, A.B., Yusuf, S.A., Trimaningsih, E.A. \& Riyono, S.H., 1997. Kisaran kelimpahan dan komposisi plankton predominan di Perairan Kawasan Timur Indonesia. Pusat Penelitian dan Pengembangan Oseanologi-LIPI. Jakarta. $139 \mathrm{hlm}$.

Anggoro, S. 1988. Analisi Tropik-Saprobik (Trosap) Untuk Menilai Kelayakan Lokasi Budidaya Laut dalam : Workshop Budidaya Laut Perguruan Tinggi Se-Jawa Tengah. Laboratorium Pengembangan Wilayah Pantai. Universitas Diponegoro, Semarang. Hal 66-90.

Elfinurfajri, F. 2009. Struktur Komunitas Fitoplankton serta Keterkaitannya dengan Kualitas Perairan di Lingkungan Tambak Undang Intensif. Departemen Manajemen Sumberdaya Perairan. Fakultas Perikanan dan Ilmu Kelautan. Institut Pertanian Bogor. Bogor.

Fachrul, M.F. 2008. Metode Sampling Bioekologi. Bumi Aksara. Jakarta.

Hadi, 1993. Metodologi Research, Penulisan Paper, Skripsi, Thesis dan Disertasi. Yayasan Penerbit Fakultas Psikologi Universitas Gajah Mada. Yogyakarta. 218 hal.

Hawkes, H.A. 1978. Invertebrate as Indicator of River Water Quality. University of Newcastle. Upon Tyae, Newcastle.

Krebs, J.C. 1985. Ecology The Experimental Analysis of Distribution and Abundance. Third Edition. Institut of Animal Recource Ecology the University of colombia. Harper and Row Publiser New York.

Nybakken, J.W. 1992. Biologi Laut suatu Pendekatan Ekologis. Alih bahasa H.M. Eidman, Koesoebiono, D.G Bengen, M. Hutomo dan S.Sukardjo. PT Gramedia Jakarta. 459 hal.

Nontji, A. 2008. Plankton Laut. Lembaga Ilmu Pengetahuan Indonesia (LIPI), Jakarta. $331 \mathrm{hlm}$.

Odum, 1993. Dasar-dasar Ekologi. Edisi ke III. Diterjemahkan oleh Tjahjono, S. Gajah Mada University Press. Yogyakarta: $201-250 \mathrm{hlm}$. 
Pamungkas, R.T. 2014. Analisis Komposisi Struktur Komunitas Fitoplankton dan Saprobitas Perairan serta Kualitas Air di Perairan Pulau Panjang Kabupaten Jepara. FPIK. Universitas Diponegoro. Semarang

Sachlan, M., 1982. Planktonologi. Fakultas Peternakan dan Perikanan UNDIP,. Semarang pp 1101.

Setiadi, A. 1999. Ekologi Dinoflagellata. Oseana, 26(4):21-30.

Soegianto, A. 2004. Metode pendugaan pencemaran perairan dengan indikator biologis. Airlangga University Press

Sugito \& Sugandi. 2008. Urgensi Penentuan dan Penegakan Hukum Kawasan Sempadan Pantai. Jurnal Geografi. 8(2):100.

Thoha, H. 2004. Kelimpahan Plankton Di Perairan Bangka-Belitung Dan Laut Cina Selatan, Sumatera, Mei - Juni 2002. Makara Sains, 8(3):96-102.

Yamaji, I. 1979. Illustrations of the marine plankton of Japan. Hoikusha Publishing Co. 